\title{
КОНЦЕПТ ДЕНЬГИ КАК ТРИГГЕР КОММУНИКАТИВНОГО САБОТАЖА (НА МАТЕРИАЛЕ ИНТЕРНЕТ-ИНТЕРВЬЮ)
}

\author{
Е. Э. Яренчук, Е. В. Чаплыгина
}

Курский государственный университет

\section{CONCEPT MONEY AS A TRIGGER OF COMMUNICATIVE SABOTAGE (AS EXEMPLIFIED IN YURY DUD'S INTERNET SHOW)}

\author{
E. E. Yarenchuk, E. V. Chaplygina \\ Kursk State University
}

\begin{abstract}
Аннотация: весьма актуальным сегодня является вопрос описания формирования и течения интернет-коммуникаџии ввиду популярности и востребованности интернет-контента у массовой аудитории. Так, реализация и функиионирование кониепта «деньги» в интернет-интервью, по мнению авторов настоящей статьи, может способствовать скрытой конфронтации ситуации речевого общения со стороны собеседника - использованию таких речевых средств, которые не только позволяют избежать прямого ответа на поставленный интервьюером вопрос, но и повернуть разговор в выгодное для себя русло, поменять тему беседы. Авторами преследуется иеель описания способности концепта «деньги», вербализированного в реплике-вопросе интернет-интервью, вызывать чувство фрустрации у собеседни$\kappa a$, которое, в свою очередь, заставляет последнего саботировать вопрос интервьюера. Под коммуникативным саботажем в настоящей статье понимается такое средство речевой манипуляции, которое используется говорящим с иелью воздействия на сознание реципиента и навязывания аудитории своего мнения. Методом сплошной выборки были определены отрывки интервью, включаюшие вопросы, в которых реализуется концепт «деньги», и проанализированы ответы на данные вопросы. В исследуемых интернет-интервью концепт «деньги» вербализуется разнообразными лексическими средствами: числительными, наименованиями валют, просторечными и жаргонными лексемами, заимствованиями из английского языка и т. д. Использование коммуникативного саботажа участниками интервью было зафиксировано практически во всех рассматриваемых фрагментах интернет-программы, однако также подчеркивается, что в некоторых случаях рециипент готов давать ответы на поставленные провокаичонные вопросы и не саботировать речевую ситуачию - здесь необходимо учитьвать как специфику коммуникативной ситуачии, так и отношения между собеседниками, а также особенности личности говорящего.
\end{abstract}

Ключевые слова: концепт «деньги», коммуникативный саботаж, реализация концепта, саботирование, интернет-дискурс, интернет-иоу.

Abstract: the question of describing the formation and course of Internet communication in view of the popularity and demand for Internet content among a mass audience is quite relevant today. The implementation and functioning of the concept "money" in an online interview, according to the authors of this article, can contribute to a hidden confrontation of the situation of speech communication from the interlocutor - the use of such speech tools that help not only avoid a direct answer to the question posed by the interviewer, but also turn the conversation into a favorable course for themselves, change the topic of conversation. The authors aim to describe the ability of the concept "money" in the replica-question of an Internet interview to cause a sense of frustration of the interlocutor, which in its turn makes the latter sabotage the interviewer's question. In the article, communicative sabotage is considered a means of speech manipulation that is used by a speaker to influence the consciousness of the recipient and impose his opinion on the audience. Using a continuous sampling method, the authors determined the extracts of interviews, including questions in which the concept "money" is implemented, and the

(C) Яренчук Е. Э., Чаплыгина Е. В., 2021

Контент доступен под лицензией Creative Commons Attribution 4.0 License.

The content is available under Creative Commons Attribution 4.0 License. 
answers to these questions were analyzed. In the interviews under study the concept "money" is verbalized by a variety of lexical means: numerals, names of currencies, colloquial and jargon lexemes, borrowings from English, etc. The use of communicative sabotage by interview participants was recorded in almost all the fragments of the Internet program under consider. However, it is underlined that in some cases, a receptor is ready to give full answers to raised questions and not to commit sabotage in the course of communication - the peculiarities of the communicative situation as well as relationships between interlocutors and characteristic features of a speaker should be considered here.

Key words: concept “money”, communicative sabotage, concept realization, sabotaging, Internet discourse, Internet show.

\section{Введение}

Современная лингвистическая наука предполагает исследование и описание языковых явлений в неразрывной связи с человеком. Одним из базовых понятий антропоцентрического подхода в исследованиях является понятие концепта, который выступает и в качестве ментальной, и в качестве языковой единицы. В. И. Карасик дает следующее определение концепта: «Концепт - это хранящаяся в индивидуальной либо коллективной памяти значимая информация, обладающая определенной ценностью, это переживаемая информация» [1, с. 90]. В понимании А. П. Бабушкина «концепт - любая дискретная единица коллективного сознания, которая отражает предмет реального или идеального мира и хранится в национальной памяти носителей языка в виде... вербального обозначения субстрата» [2, с. 95]. По определению В. А. Пищальниковой «концепт - специфическая модель значения, акцентирующая роль языкового значения в познавательных процессах» [3, с. 218]. А. Вежбицкая предлагает следующую экспликацию термина: концепт - это «объект идеального мира, имеющий имя и отражающий культурно-обусловленное представление человека о мире» [4, с. 47]. В своей работе исследователь последовательно исходит из того, что концепт - это идеальный объект, существующий в психике, поэтому одному и тому же имени (слову) в психике разных людей могут соответствовать разные ментальные образования, т. е. за одним и тем же словом в сознании разных людей могут стоять разные концепты. Таким образом, в нашем исследовании под концептом мы понимаем «оперативную единицу человеческого сознания, имеющую многомерную структуру и являющуюся результатом познавательной деятельности личности и общества. Такая единица может быть вербализована разными способами в зависимости от коммуникативной ситуации, но, как правило, в языке имеются более или менее типичные средства вербализации конкретных концептов, закрепленные в данной культуре в результате ее исторического опыта» [5, с. 7].

Причастность к окружающей действительности индивида, ее восприятие и отношение к нему во многом определяются комплексом функционирующих в языке средств, служащих формированию кон- цептуального образа мира: «...овладевая языком, и в частности значениями слов, носитель языка начинает видеть мир под углом зрения, подсказанным его родным языком, и сживается с концептуализацией мира, характерной для соответствующей культуры. В этом смысле слова, заключающие в себе лингвоспецифичные концепты, одновременно “отражают" или “формируют” образ мышления носителей языка» $[6$, c. 4$]$.

Настоящая статья посвящена описанию функционирования концепта «деньги» в вопросах-репликах интернет-интервью. Авторы статьи ставят своей целью выявление способности данного концепта в контексте реального общения вызывать чувство фрустрации у собеседника, что может обусловливать использование таких речевых средств, которые способствуют вуалированию ответа или уходу от ответа и, таким образом, служат цели манипулирования сознанием реципиента, т. е. коммуникативного саботажа.

Термин «саботаж» активно используется в юриспруденции, истории, но сегодня учеными выделяется и коммуникативный саботаж. Т. М. Николаева рассматривает «коммуникативный саботаж» как высказывание, при помощи которого можно манипулировать массовым сознанием, и называет такой прием «лингвистической демагогией» [7]. По мнению Е. Л. Доценко, «коммуникативный саботаж»-своего рода информационное давление на собеседника реакция адресата на высказывание адресанта, в которой «предыдущая реплика игнорируется, а в ответ вводится новое содержание» [8]. В. Ю. Андреева понимает коммуникативный саботаж как «диалогический прием оказания речевого воздействия, выражающий скрытое сопротивление человека и направленный на игнорирование содержательной части высказывания собеседника с целью уклонения от общения, искажения или сокрытия информации» [9, c. 11]. Таким образом, коммуникативный саботаж является «своего рода средством речевой манипуляции, используемым говорящим с целью воздействия на сознание реципиента и, таким образом, навязывания аудитории своего мнения» [10].

Актуальность настоящего исследования состоит в изучении концепта «деньги» в парадигме когнитив- 
но-дискурсивного метода исследования языка - функционирование языковых единиц, вербализующих исследуемый концепт, в контексте реального общения может провоцировать, на наш взгляд, использование продуцентами коммуникативного саботажа. Мы полагаем, что концепт «деньги» при использовании в реплике-вопросе в режиме диалогического общения заставляет индивида продумывать возможные пути вуалирования ответа или попросту саботирования вопроса собеседника. «Особое внимание следует обратить на диалогичность или прямую коммуникацию в ситуации речевого взаимодействия, детерминирующей использование коммуникативного саботажа, так как саботирование происходит лишь в ответ на реплику собеседника» [11]. Уточним, что концепт «деньги» был выбран нами не случайно, ведь в системе человеческих ценностей он занимает одно из самых важных мест - вопрос ценности предметов не теряет своей актуальности вот уже тысячи лет, а отношение к деньгам меняется в зависимости от происходящих в обществе событий. Подчеркнем, что вопросы о деньгах, материальной ситуации или уровне дохода всегда считались бестактными и неприличными, финансовые проблемы было принято обсуждать в тесном кругу семьи или с близкими друзьями, однако сегодня, когда телевидение и Интернет делают практически любой вид коммуникации достоянием общественности, все чаще можно узнать об уровне дохода представителей власти, политической элиты, звезд шоу-бизнеса, врачей, учителей и т. Д.

Тем не менее отношение к деньгам в современном обществе весьма неоднозначно, мы полагаем, что в зависимости от индивидуального опыта реакция на вопросы о деньгах может быть весьма непредсказуемой и в некоторых случаях служить цели прекращения общения или смены темы, т. е. использования коммуникативного саботажа. Более того, если в личной беседе ответа на такой вопрос можно избежать, то в теле- или интернет-интервью - нет.

Действительно, сегодня вербальную реализацию концепта «деньги» можно проследить в различных телевизионных и интернет-программах разговорного жанра, в связи с чем интересным представляется вопрос коммуникативного саботирования в ситуации речевого общения на тему о деньгах в ток-шоу разговорного жанра, предлагаемых в сети Интернет.

«Самым оперативным, а потому важным источником предоставления информации сегодня является Интернет. В современных условиях Интернет является объектом исследования многих областей научного знания: лингвистики, когнитивистики, журналистики, лингвокультурологии и др. Большинство исследователей единодушны во взглядах на возрастание доминирующей роли Интернета по сравнению с другими средствами коммуникации. Интернет вытесняет другие медиа-источники, когда речь заходит о необходимости как можно быстрее узнать новости о том или ином событии» [12, с. 27].

Разделяя данное мнение, считаем необходимым добавить, что исследование интернет-контента является весьма перспективным и показательным - сегодня все большее внимание привлекают интернет-проекты; контент всемирной паутины наполнен всевозможными аналогами телевизионных программ, однако не ограничен цензурой и, следовательно, разнообразен с точки зрения предлагаемых к обсуждению тем, волнующих широкую аудиторию. Можно сказать, что популярные ранее телевизионные жанры «перенеслись» в интернет-среду, обрели «свободу», стали более смелыми, гибкими, так как в большей мере они носят неформальный характер, вбирающими и отражающими все новое в языке и речи. В аспекте лингвистической специфики интернет-программы не подвержены жестким ограничениям, в силу чего вербальное содержание исследуемого контента представляет собой «живой» язык, предполагает спонтанность и неподготовленность речи участников беседы.

\section{Результаты исследования}

Материалом настоящего исследования послужило нашумевшее авторское интернет-шоу Юрия Дудя интернет-программа, в рамках которой автор и ведущий проводит интервью с представителями политики и телевидения, музыкальной индустрии, кино и т. д. Со времен первого выпуска данного шоу количество просмотров насчитывает более одного миллиарда, интерес аудитории не угасает, и программа привлекает все большее число новых подписчиков.

Исследуемая интернет-программа Ю. Дудя предполагает беседу ведущего и гостя; в программе затрагиваются различные темы, интересующие широкую аудиторию, задаются провокационные, откровенные и прямолинейные вопросы, а каждый выпуск шоу вызывает широкий резонанс. Одним из самых знаменитых и ожидаемых вопросов ведущего является вопрос «Сколько ты зарабатываешь? / Сколько Вы зарабатываете?». Нами было проанализировано 6 выпусков интернет-шоу длительностью от 59 минут до 2 часов 47 минут (всего 9 часов 36 минут интернет-трансляции). Методом сплошной выборки были определены отрывки интервью, включающие вопросы, в которых реализуется концепт «деньги». Мы предлагаем обратиться к нескольким отрывкам данных интервью с целью анализа реакции адресантов на интересующий нас вид вопроса и выявления случаев коммуникативного саботажа в ответных репликах реципиентов.

Обратимся к примеру, взятому из интервью с Ксенией Собчак, политиком, журналистом, обще- 
ственным деятелем, теле- и радиоведущим. Отметим, что беседа проходила накануне ее президентской кампании 2018 г. [https:/www.youtube.com/watch?v $=$ wpfpey_0G5A\&ab_channel=\%D0\%B2\%D0\%94\%D1 $\% 83 \% \mathrm{D} 0 \% \mathrm{~B} 4 \% \mathrm{D} 1 \% 8 \mathrm{C}]$ :

- Forbs оченил твой последний заработок за прошльй год, заработок за последний год в 2100000 долларов.

- То есть все-таки, то есть все-таки Юра был бы не Юра, если бы он про бабки не спросил...

- Насколько это близко к правде? 2 миллиона 100 за год - насколько это близко к правде?

- Нууу, имеет... как тебе говорил один из твоих героев: имеет право на существование эта ичифра, т. е. где-то, наверное...

- Насколько я понимаю, средняя иена твоих корпоратов - это 25, ну в среднем 30000 евро за мероприятие. Насколько тебе придется сейчас от них отказаться? Будешь ли ты их вести во время президентской кампании, и это очень важно, учитыввая, что впереди Новый год, а это бабки, бабки, $\underline{\text { бабки? }}$

- В жизни да, вот в жизни надо уметь жертвовать в том числе, Юра, и деньгами, я знаю, что тебе этого не понять, но все же. Поверь мне на слово. Надо жертвовать деньгами иногда ради большой идеи. Поэтому я сейчас выполню все обязательства, которые я уже на себя взяла, их, слава богу, немного, они не касаются новых годов и так далее. Я закончу с рекламой, я закончу с корпоративами на этот период и, естественно, никаких на сегодняшний момент заказов я не беру, поэтому все-таки бабло не должно победить добро.

В предлагаемом диалоге в вопросительных репликах концепт деньги реализуется путем употребления различных лексических единиц, в том числе числительных, наименований валют (2 100000 долларов, 30000 евро) и просторечных, жаргонных лексем (бабки, бабло). В ответных репликах видим использование реципиентом коммуникативного саботажа: К. Собчак не дает прямых ответов на поставленные вопросы, часто пытается направить разговор на интервьюера, называя его имя или обращаясь к нему. Выше мы отметили, что интервью состоялось накануне президентской кампании К. Собчак, что не могло не отразиться на ее речевом поведении - использование коммуникативного саботажа в ответ на вопросы, реализующие концепт деньги, позволяет говорящему сформировать определенный имидж о себе у многочисленной аудитории - потенциального электората.

В следующем отрывке интервью с Леонидом Парфеновым, журналистом, телеведущим, писателем, реализация концепта деньги также приводит к использованию адресатом коммуникативного саботажа
[https://www.youtube.com/watch?v=t6i4ElZV1K0\&ab channel $=\%$ D0 $\%$ B2 $\%$ D0 $\% 94 \%$ D $1 \% 83 \%$ D0 $\%$ B $4 \%$ D $1 \%$ $8 \mathrm{C}]$ :

- Тех денег, которые Bы получаете за книги и за фильмы, которые Bы выпускаете в среднем раз в полтора года, достаточно для того, чтобь нормально жumb?

- Ну, я ещуе в рекламе снимаюсь, если уж Вы хотите инвентаризировать все мои доходь. Hет, нет, мне достаточно, я не нуждаюсь ни в чем большем, чем у меня есть. Я давно вот в этом стандарте и потребления, и возможностей, условий, ни большего не жду, ни меньшего не боюсь, как-то спокойно.

Первая реплика в ответе Л. Парфенова содержит явный сарказм и попытку ухода от ответа. Тем не менее адресат дает довольно развернутый ответ на заданный вопрос в отличие от следующего гостя анализируемой интернет-программы:

- Чем Bы зарабатываете кроме программы?

- А Вам-то какое дело?

- Ээээээээ... Последующая серия вопросов... Ну, во-первых, нам, нашей программе прямое дело, потому что мы в каждой программе говорим про деньги, если вот здесь не появляется титр с дзинем (делает соответствуюшчий жест, указываюший на нижнюю часть экрана, где появляется надпись «титр с дзинем», и включается звук звенящих монет) хотя бы раз, то можно считать, что... программу под нож можно отпускать. Вы поймете, почему я спрашиваю, из вопроса, который через два в моем списке располагается.

- Нет, ну дело в том, что я зарабатываю своей профессией, я иногда зарабатываю выступлениями...

- Ну, собственно все выступления этой недели, они же были за гонорар?

- Не все, но почти все. И всё. По-моему, всё. Может, Вы что-то напомните?

- Нет. Я люблю проводить инвентаризацию, но в Вашем случае мне ничего больше на ум не приходит [https://www.youtube.com/watch?v=wg-TMymYSw E\&ab_channel=\%D0\%B2\%D0\%94\%D1\%83\%D0\%B4 $\%$ D $1 \% 8 \mathrm{C}]$.

Отвечая на вопрос Ю. Дудя «Чем Вы зарабатываете кроме программы?», Владимир Познер, журналист, радиоведущий, телеведущий, писатель, явно и довольно агрессивно саботирует реплику говорящего. Ответ вопросом на вопрос вообще является довольно распространенной тактикой коммуникативного саботажа - c ее помощью говорящий не только уходит от ответа и выигрывает время на обдумывание последующей реплики, но и, как в данном случае, выражает свое отношение к собеседнику и вопросу. Также отметим большое количество лексем с отрицательным компонентом значения: нет, не все, и всё в значении только, лишь; полагаем, что подобная вербализация 
ответной реплики также свидетельствует о нежелании говорящего продолжать заданную тему.

Неуместность упомянутой «финансовой» темы вызывает у реципиента чувство фрустрации и провоцирует саботирование. Аналогичную ситуацию наблюдаем в следующем отрывке из интервью Ю. Дудя с Моргенштерном, главным шоуменом России-2020 [https://www.youtube.com/watch?v=AR6ovvs6Ihg\&t $=6149 \mathrm{~s}]$ :

- Где аккумулируются эти деньги? То есть все спонсоры, они бросают их на какой-то счет, и потом это тебе приходит?

- Не, подожди, это что, для налоговой мы сейчас снимаем видео, я не понял? Да какая вам разница? Ничего не знаю. Я ничего не заработал, вообще денег у меня нет. Пи-пи-пи, пу-пу-пу... Всё по белому сделали.

Ответ вопросом на вопрос и использование отрицаний (не, не понял, ничего не знаю, нет) свидетельствуют об очевидной попытке уклонения адресата от ответа на поставленный вопрос, в котором концепт деньги вербализуется соответствующими лексическими единицами деньги, счет.

Анализ интервью также позволил сделать вывод о том, что даже если концепт деньги реализуется в вопросе, не затрагивающем темы частного характера, а относящемся к общественным проблемам, то, тем не менее, саботирование имеет место, и мы полагаем, что это связано с намерением продуцента построить ответную реплику таким образом, чтобы убедить аудиторию в своей правоте и сформировать определенное мнение у собеседника и, безусловно, аудитории. В данной связи интересным представляется интервью Ю. Дудя с Сергеем Гуриевым, доктором экономических наук, ректором Российской экономической школы в 2004-2013 гг,, главным экономистом Европейского банка реконструкции и развития в 2015-2019 гг. [https://www.youtube.com/watch?v= Bj7q5VAf8-w\&t=2144s\&ab_channel $=\%$ D0 $\%$ B2\%D0\% $94 \% \mathrm{D} 1 \% 83 \% \mathrm{D} 0 \% \mathrm{~B} 4 \% \mathrm{D} 1 \% 8 \mathrm{C}]$ :

1) - Вы всегда говорите, что экономика растет, но параллельно я читаю новости о том, что количество бедных в России сейчас почти 21 миллион, а количество людей без теплого туалета - это 1,5 десятка миллионов человек. В каком месте тогда этот pocm?

- Вы очень правильный задали вопрос. Растет, но не для всех. Растет в среднем и в ичелом, но количество бедных действительно растет, реальные доходы населения падают.

2) - Еще одно из телевизора: госдолг США $100 \%$ ВВП, у России этого долга то ли нет, то ли практически нет. Ну? Им конец, а нам нет?

- Но Bы знаете, это действительно хороший вопрос. Например, в Украине госдолг существенно ниже, чем в США, в процентах к ВВП, но грубо говоря, украинские иенные бумаги являются более рискованными, чем американские, потому что американский госдолг обеспечен будущуим американской экономики и уверенностью в том, что Америка просто так не объявит дефолт.

В предлагаемых к рассмотрению примерах концепт деньги реализуется в соответствии с обсуждаемой темой и весьма неожиданно: беднье, люди без теплого туалета, рост экономики, ВВП, госдолг. Использование коммуникативного саботажа в ответных репликах обоих отрывков интервью начинается с комментария адресата «хороший вопрос», что позволяет продуценту расположить собеседника к себе, сформировать собственный положительный образ, а также обдумать и сформулировать последующую реплику необходимым ему образом.

Обратимся к следующему примеру из интервью с Моргенштерном:

- Сколько денег надо ввалить, чтобы открыть ресторан?

- Угадай, сколько здесь денег. Давай... Смотри, здесь не было вообще ничего, здесь всё перевернули, всё полностью в штукатурке, поль, всё! Сколько вложено сюда?

- Ну, я угадываю: 20 миллионов рублей.

- Hem.

- Больше?

- Да.

- 30 миллионов.

- Больше.

- Блин.

- Чувак, мне все говорят, что я трачу на безделушки (обсценная лексика заменена нейтральной авторами статьи) деньги, вот это мое самое огромное... трата денег за всю историю моей жизни.

- И сколько?

- Миллион долларов!

Настоящий пример интересен тем, что интервьюируемый вместо ответов на поставленные вопросы, в которых также происходит реализация концепта деньги, провоцирует своеобразную игру в угадайку. Мы полагаем, что подобное речевое поведение целиком и полностью обусловлено личностью говорящего и продиктовано его намерением делать из любого события шоу: Моргенштерн - известный сегодня исполнитель и шоумен, который обрел популярность благодаря скандальным роликам и видео, следовательно, использование коммуникативного саботажа в его высказываниях продиктовано желанием поддержания данного имиджа. Отметим также, что в его интервью весьма частотно использование обсценной лексики, что также говорит об определенных целях, достигаемых путем применения названных лексем. Стремление сохранения необходимого 
имиджа, бесспорно, достигается путем использования коммуникативного саботажа, как в следующем примере:

- А зачем ты решил делать гив? Гив же считается прям стьцной штукой.

- Почему это? То, что типа там людей обманьвают? (обсценная лексика заменена нейтральной авторами статьи)

- То, что люди, которые таким образом приходят в подписчики, Инстаграм вроде как пессимизирует их выдачи, и лайков, просмотров и всего у них становится меньше, чем было раньше, подписота вырастает, а просто эти посты становятся видны гораздо меньшему количеству людей.

- А мне-то что собственно с этого? Я как бы денег заработал, машину разыграл, я же никого не заставлял у себя места спонсорские покупать, все, кто хотел, купил.

- Сколько ты заработал на этом?

- Очень много. Еще 10 таких же машин.

Приведенный пример довольно интересен с точки зрения реализации концепта деньги с помощью использования многочисленных заимствований из английского языка в русский язык, что объясняется популярностью социальной сети Инстаграм и Интернета в целом: гив, пессимизировать, лайк, подписота (пренебрежительное от подписчики). Данные лексемы широко известны среди пользователей сети Интернет в первую очередь своим свойством описывать финансовое благополучие их обладателей: чем больше лайков и подписчиков, тем больше возможностей заработать.

Так в приведенном примере вопрос об очередном способе получения дохода саботируется адресатом, как и подчеркивалось выше, с целью сохранения собственного имиджа.

Отметим, что в анализируемых интервью реализация концепта «деньги» не всегда ведет к саботированию реплики интервьюера. Так, в следующих диалогах адресаты дают прямые развернутые ответы на поставленные вопросы:

1) отрывок из интервью Ю. Дудя с Ириной Горбачевой, актрисой [https://www.youtube.com/watch?v= sRwXMnLgcK4\&t=1041s]:

- Инстаграм сейчас твой основной доход? Он же приносит больше, чем кино?

- Да, да. Это основной источник моего дохода.

- У тебя есть какой-то лимит по тому, сколько ты рекламных постов в месяц можешь выпустить?

- Вообще есть, есть. Я стараюсь это делать не больше двух тире трех постов в месяи.

- В месяи?

- В месяи, да. Стараюсь, вот. Но не всегда это получается, потому что иногда в один месяи больше спрос, в другой месяи вообще нет спроса.
- Я правильно понимаю, что твой пост в инстаграме стоит в районе трехсот тысяч рублей?

- Да.

- Как изменилась твоя жизнь в последний год с точки зрения кэша? Стала ли ты состоятельной леди?

- В иелом да, я думаю, что да. Не думаю, а да, конечно, да, то есть я стала в разы больше зарабатыввать, чем это было, допустим, до моей популярности в Инстаграме. Благодаря Инстаграму мне удалось заработать денег и купить себе квартиру и сделать в ней ремонт.

2) отрывок из интервью Ю. Дудя с Сергеем Гуриевым:

- Я понимаю, что вопрос звучит странно, но все равно... Вам кто-нибудь предлагал деньги за мнение по этому делу «Эксперт»?

- Нет, мне никто не предлагал этих денег, никогда и на самом деле я никогда не получал денег от Ходорковского, «Юкаса», его партнеров ни до того, как я уехал из России, ни после того, как я уехал из России. Следствие показало, что был момент, когда какие-то структуры, аффилированные с компании «Юкас», сделали пожертвование в бюджет Российской экономической школь, но это было в 2003 или 2004 г., когда я на самом деле не работал в РЭШ. У меня был такой отпуск, когда я уехал на год преподавать в Принстон. И в этом смысле эти деньги пришли после того, как я уехал, они были потрачень до того, какя вернулся назад из Принстона в Москву, т. е. я к этим деньгам вообще никакого отношения не мог иметь.

3) отрывок из интервью Ю. Дудя с Моргенштерном:

- А где ты лаве взял, чтобы приехать?

- Ну, так я тогда уже рекламировал казино Вул-

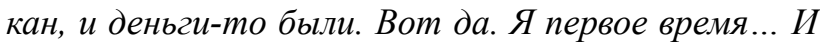
там... Что там еще было? Короче, всякие лохотроны рекламировал, как только у меня ҮоиТиье стрельнул. Мне не стылно. Вот я рекламировал лохотроны, онлайн-казино... Такое было.

- Сколько интернет-казино дает за рекламу?

- Мне тогда, по-моему, по 100000 давали за виdoc.

Мы полагаем, что продуцирование прямого ответа, отсутствие намерения саботировать вопрос, желание подробно описать интересующую ситуацию целиком и полностью зависит от личности говорящего и взаимоотношений между интервьюером и интервьюируемым, более того, на наш взгляд, возрастное равенство, а также схожий род их деятельности, как, например, в случае с интервью Моргенштерна и И. Горбачевой, делают коммуникативную ситуацию более располагающей к откровенному разговору. Отсутствие коммуникативного саботажа в ответной 
реплике на вопрос с явной реализацией концепта деньги С. Гуриева обусловлено желанием «оправдаться», улучшить свой имидж - при саботировании вопроса могла бы возникнуть двусмысленность.

\section{Выводы}

Следуя цели исследования - описать реализацию концепта «деньги» в вопросительной реплике интервьюера как стимул к использованию коммуникативного саботажа, с помощью которого реципиент не просто находит способ избежать прямого ответа на «неудобный» вопрос, но и навязать массовой аудитории - адресатами анализируемой программы являются миллионы человек - свое мнение, улучшая тем самым собственный имидж, авторы статьи пришли к следующим выводам.

1. В рассматриваемом интернет-проекте вопросы, в которых реализуется концепт «деньги», являются весьма частотными. Реализация концепта «деньги» в вопросительной реплике может способствовать продуцированию реципиентом коммуникативного саботажа по разным причинам: нежелание отвечать на вопрос, стремление уйти от ответа или «выиграть» время на его подготовку, намерение сформировать положительное впечатление о себе и своей деятельности или необходимого общественного мнения, навязывание своей точки зрения массовой аудитории. Важно, что, принимая участие в подобных программах, интервьюируемые осознают массовость аудитории и зачастую намеренно дают согласие на подобные беседы и вопросы.

2. Концепт «деньги» в интернет-интервью вербализуется разнообразными лексическими средствами: числительными, наименованиями валют, просторечными и жаргонными лексемами, заимствованиями из английского языка и т. д. (2 100000 долларов, 30000 евро, заработок, зарабатывать, стоить, бабки, бабло, деньги, кэи, лаве, иена корпоратов, счет, лимит, основной доход, бедные, люди без теплого туалета, состоятельная леди, рост экономики, ВВП, госдолг, гив, пессимизировать, лайк, подписота (пренебрежстельное от «подписчики»).

3. Вербальная реализация концепта деньги в вопросе интернет-интервью в большинстве случаев ведет к использованию коммуникативного саботажа, т. е. концепт деньги выступает своеобразным триггером попытки сокрытия истины и навязывания аудитории собственного мнения, «удобного» саботирующему; в некоторых случаях использование коммуникативного саботажа позволяет участникам интервью получить дополнительное время на формулирование ответа, корректного, по их мнению.

4. Саботирование вопроса, содержащего концепт деньги, происходит не всегда - использование коммуникативного саботажа зависит от языковой лично- сти, обладающей собственным уникальным опытом и преследующей конкретные цели в данной коммуникативной ситуации.

\section{ЛИТЕРАТУРА}

1. Карасик В. И. Языковой круг : личность, концепты, дискурс. Волгоград : Перемена, 2002. 477 с.

2. Бабушкин А. П. Типы концептов в лексико-фразеологической семантике языка. Воронеж : Изд-во Воронеж. гос. ун-та, 1996. 104 с.

3. Пищальникова В. А. Значение и концепт // Вестник МГЛУ. 2007. Вып. 541. Серия Лингвистика.

4. Вежбиикая A. Семантические универсалии и описание языков / пер. с англ. А. Д. Шмелева ; под ред. Т. В. Булыгиной. М. : Языки русской культуры, 1999. $780 \mathrm{c}$.

5. Палеева E. В. Способы вербализации концепта деньги средствами английского и русского языков : автореф. дис. ... канд. филол. наук. Курск, 2010.

6. Вежбицкая А. Понимание культур через посредство ключевых слов / пер. с англ. А. Д. Шмелева. М. : Языки славянской культуры, 2011. 288 с.

7. Николаева Т. М. Лингвистическая демагогия // Прагматика и проблемы интенсиональности. М., 1988. С. $154-165$.

8. Доценко Е. Л. Психология манипуляции : феномены, механизмы и защита. М. : ЧеРо ; Изд-во МГУ, 1997. $344 \mathrm{c}$.

9. Андреева В. Ю. Стратегии и тактики коммуникативного саботажа : автореф. дис. ... канд. филол. наук. Курск, 2009. 24 с.

10. Яренчук E. Э. Коммуникативный саботаж и речевая манипуляция в медиадискурсе России и США // Теория языка и межкультурная коммуникация. 2020. № 1 (36). URL: https://api-mag.kursksu.ru/api/v1/get_ pdf $/ 3542 /$

11. Яренчук Е. Э. Когнитивная модель коммуникативного саботажа в дискурсе аналитического ток-шоу // Теория языка и межкультурная коммуникация. 2019. № 2 (33). URL: https://api-mag.kursksu.ru/api/v1/get_ pdf $/ 3262 /$

12. Антонова С. Н. и др. Стратегия выстраивания новостного дискурса в интернет-медиа // Вестник Воронеж. гос. ун-та. Сер.: Лингвистика и межкультурная коммуникация. 2019. № (1). С. 25-33.

\section{REFERENCES}

1. Karasik V. I. YAzykovoj krug: lichnost', kontsepty, diskurs [Language circle: personality, concepts, discourse]. Volgograd: Peremena, 2002. 477 p.

2. Babushkin A. P. Tipy kontseptov v leksiko-frazeologicheskoj semantike yazyka [Types of concepts in lexical and phraseological semantics of language]. Voronezh: Izdvo Voronezhskogo gosudarstvennogo un-ta, 1996. 104 p.

3. Pishhal'nikova V. A. Znachenie i kontsept [Meaning and concept]. In: Vestnik MGLU. Vyp. 541. Seriya Lingvistika. Moscow, 2007. 
4. Vezhbitskaya A. Semanticheskie universalii i opisanie yazykov [Semantic universals and language description]. A. Vezhbitskaya; per. s angl. A. D. SHmeleva; pod red. T. V. Bulyginoj. Moscow: YAzyki russkoj kul'tury, 1999. $780 \mathrm{p}$.

5. Paleeva E. V. Sposoby verbalizatsii kontsepta den'gi sredstvami anglijskogo i russkogo jazykov [ways of verbalization of the concept "money" by means of English and Russian languages]. PhD Dissertation Abstract. Kursk, 2010.

6. Vezhbitskaya A. Ponimanie kul'tur cherez posredstvo klyuchevykh slov [Understanding cultures through their key words]. Per. s angl. A. D. SHmeleva. Moscow: YAzyki russkoj kul'tury, 2011. 288 p.

7. Nikolaeva T. M. Lingvisticheskaya demagogiya [Linguistic demagogy]. In: Pragmatika i problemy intensional'nosti. Moscow, 1988. Pp. 154-165.

8. Dotsenko E. L. Psikhologiya manipulyatsii: fenomeny, mekhanizmy i zashhita [Psychology of manipulation: phenomena, mechanisms and protection]. Moscow: CHeRo; Izd-vo MGU, 1997. 344 p.

9. Andreeva V. YU. Strategii i taktiki kommunikativnogo sabotazha [Strategies and tactics of communicative

Курский государственный университет

Яренчук Е. Э., кандидат филологических наук, доцент кафедры перевода и межкультурной коммуникацุии

E-mail: elena_eduardovna@inbox.ru

Чапльгина Е. В., кандидат филологических наук, доичент кафедры перевода и межкультурной коммуникащчии

E-mail: elenachaplygina85@mail.ru

Поступила в редакциию 2 сентября 2021 г.

Принята к публикачии 15 октября 20212.

\section{Для циитирования:}

Яренчук Е. Э., Чапльгина Е. В. Концепт деньги как триггер коммуникативного саботажа (на материале интернет-интервью) // Вестник Воронежского государственного университета. Серия: Лингвистика и межкультурная коммуникация. 2021. № 4. С. 56-63. DOI: https://doi.org/10.17308/lic.2021.4/3811 sabotage]. PhD Dissertation Abstract. Kursk: Kursk State University, 2009. 24 p.

10. Yarenchuk E. EH. Kommunikativnyj sabotazh i rechevaya manipulyatsiya $v$ mediadiskurse Rossii i SSHA [Communicative sabotage and speech manipulation in Russian and American media discourses]. In: Teoriya yazyka i mezhkul'turnaya kommunikatsiya. 2020. No. 1 (36). URL: https://api-mag.kursksu.ru/api/v1/get_ $\mathrm{pdf} / 3542 /$

11. Yarenchuk E. EH. Kognitivnaya model' kommunikativnogo sabotazha v diskurse analiticheskogo tok-shou [Cognitive model of communicative sabotage in analytical talk show discourse]. In: Teoriya yazyka i mezhkul'turnaya kommunikatsiya. 2019. No. 2 (33). URL: https://api-mag. kursksu.ru/api/v1/get_pdf/3262/

12. Antonova S. N., Ostapenko A. S., Pletyago T. Yu. Strategiya vystraivaniya novostnogo diskursa $\mathrm{v}$ internet-media [Strategy of developing news discourse on the internet]. In: Vestnik VGU. Seriya: Lingvistika $i$ mezhkul'turnaya kommunikatsiya. 2019. No. 1. Pp. 25-33. URL: http://www.vestnik.vsu.ru/pdf/lingvo/2019/01/201901-04.pdf

Kursk State University

Yarenchuk E. E., Candidate of Philology, Associate Professor of Translation and Intercultural Communication Department

E-mail: elena_eduardovna@inbox.ru

Chaplygina E. V., Candidate of Philology, Associate Professor of Translation and Intercultural Communication Department

E-mail: elenachaplygina85@mail.ru

Received: 2 September 2021

Accepted: 15 October 2021

\section{For citation:}

Yarenchuk E. E., Chaplygina E. V. Concept money as a trigger of communicative sabotage (as exemplified in Yury Dud's internet show). Proceedings of Voronezh State University. Series: Linguistics and Intercultural Communication. 2021. No. 4. Pp. 56-63. DOI: https://doi.org/10.17308/ lic. $2021.4 / 3811$ 